\title{
Tobacco Smoking Habits, Attitudes, and Beliefs among Albanian Nurse Students
}

\author{
Ylli Vakeffliu, ${ }^{1}$ Silvana Bala, ${ }^{1}$ Rudina Pirushi, ${ }^{2}$ Kujtime Vakeffliu, ${ }^{3}$ \\ Jul Bushati, ${ }^{4}$ and Andrea S. Melani ${ }^{5}$ \\ ${ }^{1}$ Pneumologia, University Hospital Shefqet Ndroqi, Tirana, Albania \\ ${ }^{2}$ Nurse Department, Tirana Medical University, Tirana, Albania \\ ${ }^{3}$ University Hospital Madre Teresa, Tirana, Albania \\ ${ }^{4}$ Nurse Course, Kristal University, Tirana, Albania \\ ${ }^{5}$ Fisiopatologia Respiratoria, Azienda Ospedaliera Senese, Policlinico delle Scotte, Viale Bracci 3, 53100 Siena, Italy
}

Correspondence should be addressed to Andrea S. Melani; a.melani@ao-siena.toscana.it

Received 9 October 2013; Accepted 24 November 2013

Academic Editors: R. El-Zein and Y. Shibata

Copyright (C) 2013 Ylli Vakeffliu et al. This is an open access article distributed under the Creative Commons Attribution License, which permits unrestricted use, distribution, and reproduction in any medium, provided the original work is properly cited.

\begin{abstract}
Background. Available information about tobacco smoking habits, attitudes, and beliefs among Albanian nurse students shows some discrepancies and requires further investigation. Material and Methods. Cross-sectional school-based survey using a selfadministered anonymous questionnaire in the Tirana Nurse University in December 2012 about tobacco smoking habits, attitudes, and beliefs. Results. Sixty hundred fifty one students (mean age 20.0 years; males $19 \%$, females $81 \%$ ) completed the questionnaire with an overall response rate of $87 \%$. Current smokers were $19 \%$; of this group, $37 \%$ of males and $49 \%$ of females were occasional smokers. Among current smokers, males smoked more than females ( $46 \%$ versus $13 \% ; P<0.01$ ). The knowledge about smoking was generic; only a part (24\%) of students reported having received a formal specific training on smoking related issues. The percentage of current smokers who reported at least one serious attempt to quit was 64\%. Most students (78\%) reported recent exposure to second hand smoke at home. Most students (84\%) were felt to be a model of healthy lifestyle, but only a part ( $42 \%$ of the total) was recognized to have a role in advising smokers to quit. Conclusions. Smoking habits of Albanian nurse students are not higher than those of other European countries and Albanian population of similar age and gender. Our students showed many positive attitudes towards tobacco. Targeted training about smoking related issues should be mandatory in nursing schools.
\end{abstract}

\section{Introduction}

Tobacco smoking is a major preventable cause of disease and death worldwide. The World Health Organization (WHO) encourages smoking monitoring and control programmes [1].

Health caregivers' (HCGs) tobacco smoking is important not only for their own health, but also for their exemplary behavioural role. People see HCGs as models for healthy lifestyles, including tobacco smoking. Moreover, HCGs who smoke advise against smoking less frequently than those who do not smoke. Nurses are the largest professional group among health caregivers and work in close physical proximity to patients with great responsibility for obtaining a smokefree society. Student nurses' smoking habits, attitudes, and knowledge have a key role to understand the dynamics of future smoking among general population.

The Global Health Professions Student Survey (GHPSS) [2] has been organized by WHO, the US Centers for Disease Control and Prevention, and the Canadian Public Health Association to monitor smoking habits, beliefs, and attitudes of 3rd year HCG students and enhance tobacco smoking control in low- and middle-income countries, including Albania [3]. Albania has approximately 3,600,000 inhabitants and one of the lowest per capita income in Europe and is a predominantly Muslim though largely secular Eastern European country in transition from rigidly structured socialism to a market-oriented system. Smoking rates among Albanian adolescents are not higher than those of other European countries $[4,5]$. However, the fall of communism promptly 
increased the availability and the promotion of Western-type cigarettes, while adoption of tobacco control measures lagged behind, predisposing to increased rates of smoking.

The GHPS survey was firstly performed in Albania in 2005 and, based on an overall response rate of $68 \%$, found that $41.5 \%$ of Albanian nurse students smoked, the top rate among all participating countries [5]. With respect to the first wave, the 2nd 2011 GHPS survey, carried out in 10 nursing schools and with an overall response rate of $84 \%$, found a lower smoking rate (28\%) among Albanian nurse students [6]. This discrepancy requires further investigation and more details. The present study aims to obtain data about smoking habits, attitudes, and knowledge among Albanian nurse students.

\section{Materials and Methods}

All the nurse students attending the University School of Tirana were eligible for this study. Albania has several nursing schools, but the only public school is in Tirana, where we performed our study. The Nursing School has 3 years of training and the application requires a 12 th grade of instruction.

The source of information was a self-administered questionnaire about smoking habits, attitudes, and knowledge. It was delivered without any preventive advice into the classrooms with an accompanying letter of explanations concerning the finalities of the survey on December 2012. Students filled in the questionnaire during lesson time and immediately after releasing it. The participation was anonymous and voluntary. The research protocol must have been approved by the local ethics committee. Students who were absent in the classes on the study day were excluded. No validation of the answers by objective means was undertaken. The questionnaire was based on the indications of WHO for monitoring smoking habits, attitudes, and knowledge for HCGs [7] and enriched with some items using the GHPSS experience $[2,5]$. The Albanian form had already been translated and back translated [8]. Briefly, students were asked if they had ever smoked even one or two puff of cigarettes or used any other form of tobacco. A positive response defined ever smokers, a negative never smokers. Ever smokers who had smoked on one or more days during the 30 days preceding the study and at least 100 cigarettes in their lifetime were defined current smokers. They are divided into occasional (someone who smoked less than daily) and daily (who smoke any tobacco product at least once a day). Students who did not smoke on one or more days during the 30 days preceding the study but who had smoked more than 100 cigarettes in their life were defined as formed smokers.

Chi-square statistics and multiple logistic regression were used for analysis of categorical variables, and the Student $t$ test was used for continuous variables. A $P$ value of 0.05 or less for a two-tailed test was considered significant. Data analysis was performed using the Stata v6.0 program (Stata Corp., College Station, TX, USA).
TABLE 1: Number of cigarettes smoked per day by student nurses who were daily smokers.

\begin{tabular}{lccc}
\hline & Males, $n(\%)$ & Females, $n(\%)$ & Total, $n(\%)$ \\
\hline 1-14/day & $19(53)$ & $26(76.5)$ & $45(64)$ \\
15/25/day & $9(25)$ & $8(23.5)$ & $17(24)$ \\
$>$ 25/day & $8(22)$ & 0 & $8(11)$ \\
\hline
\end{tabular}

\section{Results}

Six hundred fifty one students completed the questionnaires. The overall response rate was $86.8 \%$ of the total. Females largely outnumbered males ( $81.1 \%$ versus $18.9 \% ; P<0.001)$, while their mean age did not differ. Their mean $( \pm \mathrm{SE})$ age was $20.0( \pm 1.85)$ years, with a range going from 18 to 36 years.

Current smokers were $19 \%$. Males smoked more than females (46.4\% versus $12.7 \% ; P<0.001)$. Occasional and daily smokers were, respectively, $37 \%$ and $73 \%$ of males who smoked. Occasional and daily smokers were, respectively, $49 \%$ and $51 \%$ of females who smoked. Cigarette smoking was by far the prevalent form of tobacco consumption; only 5 students mainly used any form of tobacco other than cigarettes. We did not distinguish between students who smoked filter-tipped manufactured and hand-rolled cigarettes. The mean age at which current smokers reported to experience their first cigarette was $14.0 \pm 1.6 \mathrm{yrs}$. The daily consumption of cigarettes among respondents who were current smokers is shown in Table 1. Former smokers were $4.1 \%$ ( $5 \%$ for females and $2 \%$ for males). The percentage of current smokers who reported at least one serious attempt to quit was $64 \%$. Recent exposure to second hand smoke at home $(78 \%)$ and in the hospital premises (58\%) in the past 7 days before the study was common; current smokers were more likely to report exposure to second hand smoke at home than never smokers (OR 3.3; 95\% CI 2.1-5.1). Approximately $87 \%$ of current smokers would be happy not having started smoking; this desire was more evident in males (OR 1.7; 95\% CI 1.1-2.5).

Most students (94\%) claimed that tobacco smoking is dangerous, but only a part (27\%) recognised that it is the first known preventable cause of death in Europe. Most students recognised a relationship between tobacco smoking and coronary heart disease (86\%), lung cancer (91\%), and chronic obstructive airway diseases $(81 \%)$, but such a knowledge was possibly generic because asthma and Chronic Obstructive Pulmonary Disease (COPD) were perceived as provoked by tobacco smoking in a similar manner. Students claimed that the principal sources of information on tobacco related issues were mass media and generic journals (57\%), friends and parents (19\%), scientific journals or school, and other health care givers (24\%). Most students (70\%) recognised regular cigarette smoking as an addiction; never smokers reported this belief more commonly than current smokers (OR 3.1; 95\% CI 2.2-4.9). The details of some attitudes about smoking are displayed in Table 2, where similar findings from the GHPS surveys are also shown. More never smokers than ever smokers thought that they must give advice to patients on quitting (OR 1.8; 95\% CI 1.1-2.9). Only a minority of 
TABLE 2: Some students' attitudes on smoking in comparison to the GHPS studies.

\begin{tabular}{lccc}
\hline Year of study and number of students surveyed & 2012,651 & ${ }^{*} 2005,238$ & $2011^{\circ}, 1026$ \\
\hline Smoking ban in public places & 96 & 94 & 92 \\
HCG as a model & 84 & 23 & 95 \\
Receiving formal training in quitting & 19 & 97 & 44 \\
Getting specific training in quitting & 97 & 97 \\
\hline
\end{tabular}

The results are expressed as percentage of agreement on the total of surveyed students for each study.

* First wave GHPS study; ${ }^{\circ}$ second wave GHPS study.

students reported having received formal training in smoking cessation approaches (24\%) and having a role for advising smokers to quit (42\%), but most were aware of the value of antismoking centers (80\%), nicotine replacement therapy (54.5\%), and acupuncture/hypnosis (44\%) for helping to quit.

\section{Discussion}

Our study fpunf a smoking rate among Albanian nurse students lower than that reported (41.5\%: $57.5 \%$ for males and $36 \%$ for females) in the 2005 GHPS survey [5] and, in a lesser degree, in the 2011 (28\%; 56\% for males and $21 \%$ for females) GHPS study [6]. At least partially, the different result of our survey with respect to the previous ones may be due to the impact of Albanian tobacco control policies in nurse students. Albania signed the WHO Framework Convention on Tobacco Control (FCTC) in 2004 and, from 2006, the government established tobacco control as a public health priority, implementing ban advertising, tobacco price increases, smoke-free public places policies, and placing health warning labels on tobacco packaging. However, even if a reduction in smoking rates among Albanian general population was not found in the last years, a substantial reduction in exposure to second hand smoke in public places was described from 2007 to 2009 [9]. Another explanation of our lower smoking rates than the GHPS studies may be due to the lower average age of our sample including 1st3 rd year nurse students and not only 3rd-year ones. In a previous 2001 school-base survey carried out among 1st and 5 th year Albanian medical students, we had already shown a substantial increase in smoking rates along the studied years, increasing from $34 \%$ to $55 \%$ for males and from $5 \%$ to $34 \%$ for females [8]. Unfortunately, in the present survey we did not succeed to separate questionnaires by years of training. However, we have found high levels of occasional smokers, mainly among female nurse students. A similar observation has been described in general Albanian population of similar age [9]. This is typical of Albanian situation, as in Western countries most adults who smoke began by 18 years and were already daily smokers in early adulthood life [10]. The GHPSS did not differentiate between occasional and daily smokers $[5,6]$. We found high levels of attempts to quit in our students, greater than that one (approximately 30\%) of general population of similar age [9], suggesting a strong motivation to smoking cessation. These findings, to our opinion, strongly support that the 1st year of nurse training is a good moment to apply tobacco control programmes before smoking becomes daily and nicotine addiction is consolidating [10]. In the absence of targeted control programmes, we had already shown that nurse training may predispose to increasing smoking habits and the transition from occasional to daily smoking [11].

The Albanian Adult Tobacco Survey (AATS) based on face-to-face interviews found that current smokers were, respectively, $55 \%$ and $66 \%$ for the $18-19$ - and $20-25$-year groups of males and $23 \%$ and $28 \%$ for the $18-19$ - and $20-25$ year cohorts of females [9]. These percentages seem to suggest that Albanian nurse students do not smoke more than general population of similar age.

According to our results Albanian training nurses do not smoke more than students of other Balkanian countries. More correctly, our female nurse students had lower smoking habits than most Balkanian peers. Current smokers among nurse students were found to be $33.5 \%$ in Greece (40\% for males and $32.5 \%$ for females), 33\% in Bosnia-Herzegovina (27\% for males, $35 \%$ for females), and $34 \%$ in Serbia (32\% for males, $34 \%$ for females) $[2,5]$.

Although most students generically thought that tobacco smoking is bad, our data show some incorrect beliefs on tobacco related issues. In fact, it is well known that tobacco smoking is responsible for most cases of COPD and lung cancer, but bronchial asthma is not attributable to active tobacco smoking. The lack of specific knowledge on tobacco smoking is not surprising, given the lack of specific sources of information about smoking. The low level of specific training on smoking cessation methods, even with respect to the GHPSS, may be related to the fact that our students were interviewed along all the courses and not during their 3rd year of nurse school. Likewise, our nurse students showed a number of positive attitudes toward tobacco smoking: there was a large agreement of considering HCGs as models for people and advice against smoking and on the opportunity of banning tobacco smoking in hospitals.

This study applied only to students who were at school on the day of the survey. However, we have obtained an overall response rate over $85 \%$ of the total, suggesting that bias attributable to absence or nonresponse was limited and it is possible to draw results of value for surveyed nurse students. Another limitation is that our data were based on the selfreport of students that might underreport or overreport their habits or attitudes. However, previous studies have shown that anonymous questionnaire encourages true responses and assures good reliability [12].

\section{Conclusions}

We conclude that in Albania smoking habits of training nurses are not higher than those of other European students 
and Albanian population of similar age and gender. Our students showed many positive attitudes towards tobacco, but much more work is needed because future nurses develop their role against smoking effectively. Nursing curricula should be revised in order to organize effective tobacco control programmes and to make students able to know tobacco related issues and to manage smoking quitting.

\section{References}

[1] WHO, "Guidelines for controlling and monitoring the tobacco epidemic," Edited by WHO, Geneve, Switzerland, 1998.

[2] C. W. Warren, N. R. Jones, J. Chauvin, and A. Peruga, "Tobacco use and cessation counselling: cross-country. Data from the Global Health Professions Student Survey (GHPSS), 2005-7," Tobacco Control, vol. 17, no. 4, pp. 238-247, 2008.

[3] The GTSS Atlas, 2013, http://www.cdc.gov/tobacco/global/gtss/ tobacco_atlas/.

[4] Y. Vakeflliu, D. H. Argjiri, N. Kuri et al., "Tobacco smoking habits, attitudes and knowledge among Albanian students," Rassegna di Patologia dell'Apparato Respiratorio, vol. 21, no. 6, pp. 260-264, 2006.

[5] C. W. Warren, D. N. Sinha, J. Lee, V. Lea, and N. R. Jones, "Tobacco use, exposure to secondhand smoke, and training on cessation counseling among nursing students: cross-country data from the Global Health Professions Student Survey (GHPSS), 2005-2009," International Journal of Environmental Research and Public Health, vol. 6, no. 10, pp. 2534-2549, 2009.

[6] Albania-Nursing students, 2011, (3rd year students only) Global Health Professions Student Survey (GHPSS). Fact sheet http://nccd.cdc.gov/gtssdata/Ancillary/Documentation.aspx? SUID $=3 \& D O C T=1$.

[7] WHO, "Guidelines for the conduct of tobacco smoking surveys among health professionals," WHO/SMO/84.1., Geneve, Switzerland, 1984.

[8] Y. Vakeflliu, D. Argjiri, I. Peposhi, S. Agron, and A. S. Melani, "Tobacco smoking habits, beliefs, and attitudes among medical students in Tirana, Albania," Preventive Medicine, vol. 34, no. 3, pp. 370-373, 2002.

[9] E. Zaloshnja, H. Ross, and D. T. Levy, "The impact of tobacco control policies in Albania," Tobacco control, vol. 19, no. 6, pp. 463-468, 2010.

[10] R. S. Caraballo, S. P. Novak, and K. Asman, "Linking quantity and frequency profiles of cigarette smoking to the presence of nicotine dependence symptoms among adolescent smokers: findings from the 2004 national youth tobacco survey," Nicotine and Tobacco Research, vol. 11, no. 1, pp. 49-57, 2009.

[11] E. Boccoli, A. Federici, G. L. Trianni, and A. S. Melani, "Changes of smoking habits and beliefs during nurse training: a longitudinal study," European Journal of Epidemiology, vol. 13, no. 8, pp. 899-902, 1997.

[12] N. D. Brener, L. Kann, T. McManus, S. A. Kinchen, E. C. Sundberg, and J. G. Ross, "Reliability of the 1999 youth risk behavior survey questionnaire," Journal of Adolescent Health, vol. 31, no. 4, pp. 336-342, 2002. 


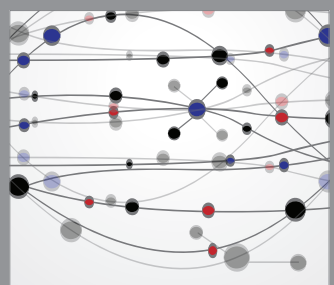

The Scientific World Journal
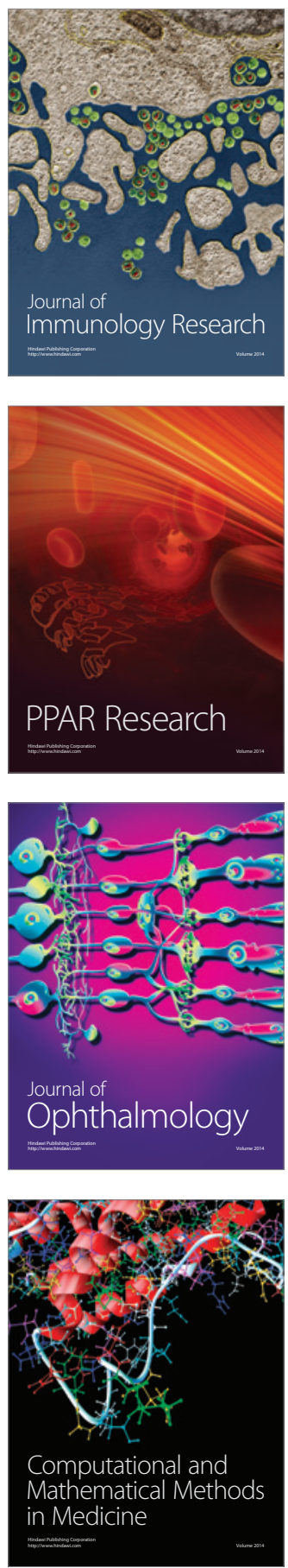

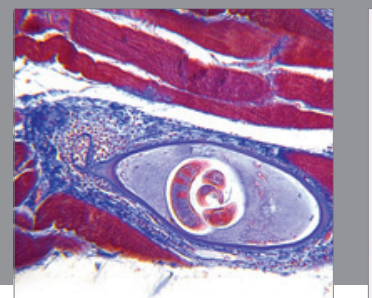

Gastroenterology

Research and Practice
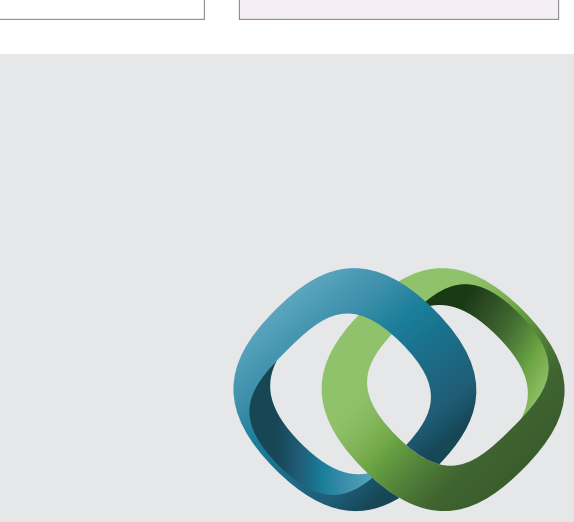

\section{Hindawi}

Submit your manuscripts at

http://www.hindawi.com
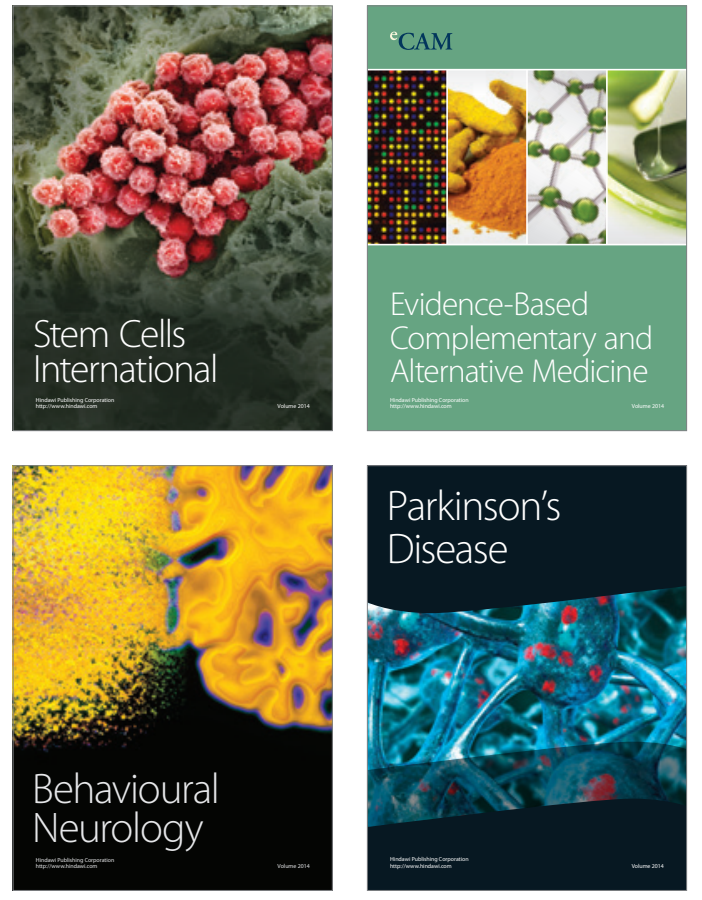
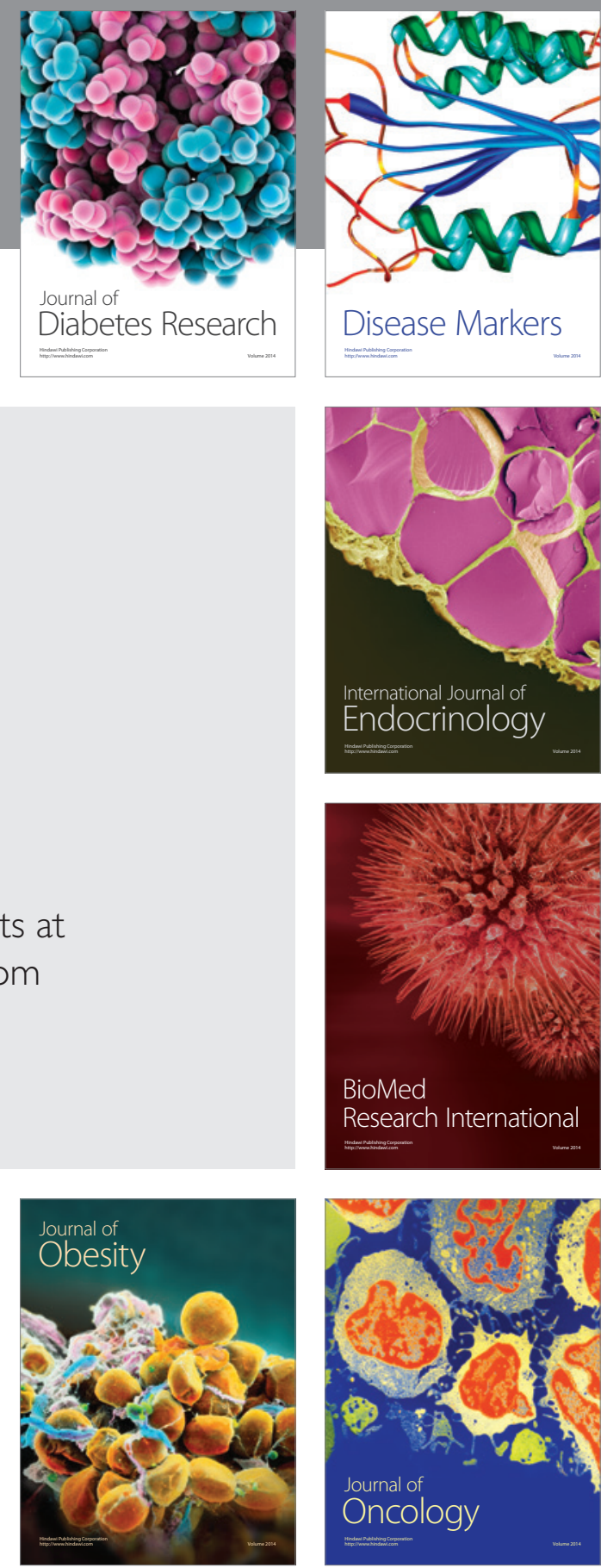

Disease Markers
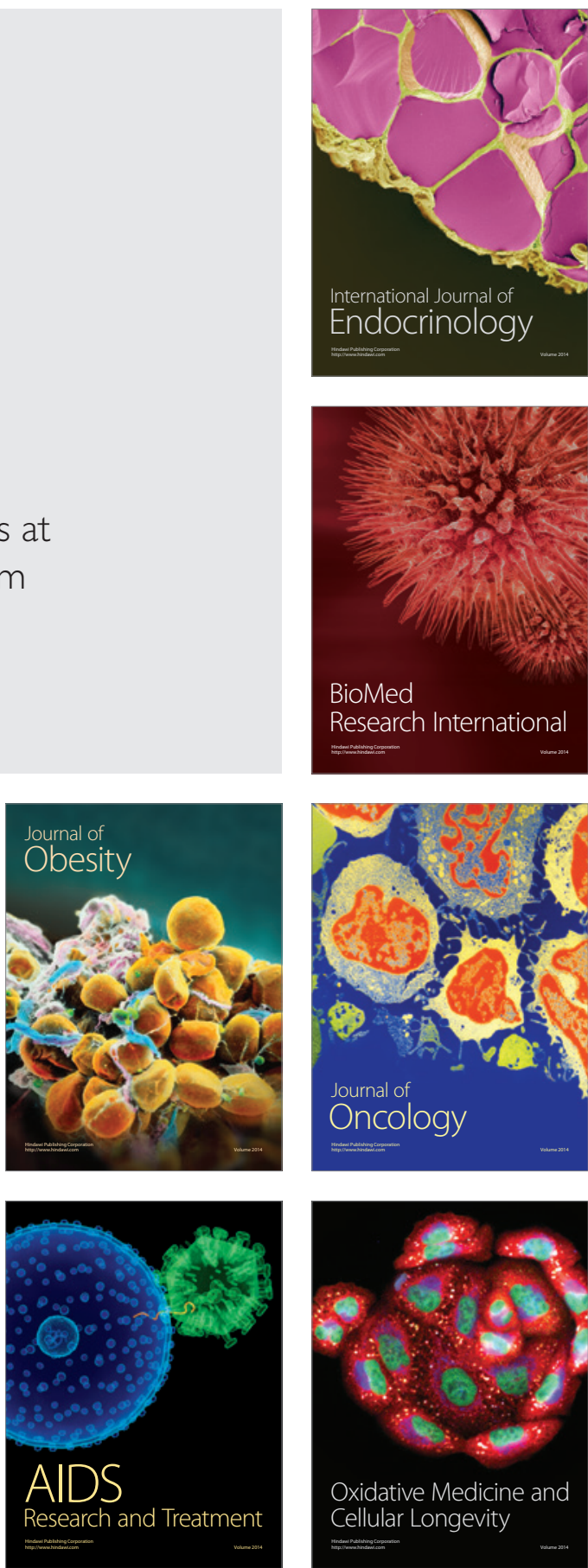